\title{
Rapid Propylene Pulsing for Enhanced Low Temperature NOx Conversion on Combined LNT-SCR Catalysts
}

\author{
Yang Zheng ${ }^{\mathrm{a}}$, Mengmeng $\mathrm{Li}^{\mathrm{a}}$, Di Wang ${ }^{\mathrm{b}}$, Michael P. Harold ${ }^{\mathrm{a}, *}$, Dan Luss ${ }^{\mathrm{a}, *}$ \\ ${ }^{a}$ Department of Chemical \& Biomolecular Engineering \\ University of Houston \\ Houston, TX 77204 \\ ${ }^{\mathrm{b}}$ Cummins Inc. \\ Columbus, IN 47201 \\ *Corresponding author: Tel. 1-713-743-4322; Fax. 1-713-743 432 \\ mharold@uh.edu (M.P. Harold), dluss@uh.edu (D. Luss)
}

\begin{abstract}
Lean reduction of NOx $\left(\mathrm{NO}+\mathrm{NO}_{2}\right)$ was conducted over combined LNT-SCR dual-layer and zoned monolithic catalysts using rapid propylene periodic pulsing into a lean feed. We investigated the effects of cycling frequency, reaction exotherm, hydrocarbon (HC) intermediates, top-layer material, LNT ceria content and catalyst configuration on the performance of dual-layer catalysts under fast propylene pulsing. High frequency propylene injection expands the operating temperature window of a conventional NOx storage and reduction (NSR) system in both low and high-temperature regions. The combination of rapid propylene pulsing and the dual-layer catalyst architecture achieves a low-temperature NOx conversion of up to $80 \%$ at a feed temperature of ca. $200{ }^{\circ} \mathrm{C}$ and relevant space velocities $\left(\sim 70 \mathrm{k} \mathrm{h}^{-1}\right)$. The working mechanisms of rapid propylene pulsing on both LNT and LNT-SCR catalysts are discussed. Fast cycling facilitates the generation of partially oxidized hydrocarbon intermediates over the LNT that can then either directly react with NOx or act as oxygen scavenger to maintain $\mathrm{Pt}$ in a reduced state for direct NO decomposition. The SCR top-layer traps partially oxygenated species that desorb from the LNT layer, enabling further production of $\mathrm{N}_{2}$ through a LNT-assisted HC-SCR pathway. Optimization of ceria content, top-layer material and catalyst configuration like SCR and PGM zoning can improve system performance at lower cost.
\end{abstract}

Keywords: NOx; Propylene; Selective Catalytic Reduction; Platinum; Low temperature NOx reduction; HC-SCR 


\section{Introduction}

The mandate for higher fuel-efficiency vehicles that meet emerging greenhouse gas (GHG) emission limits arouses an increased interest in lean burn engines with higher fuel-combustion efficiency $(\sim 20 \%$ gain in fuel economy compared to the stoichiometric combustion) [1]. Advanced powertrain strategies such as hybrid electric, turbo charging and start/stop techniques boost the fuel efficiency but produces a lower enthalpy exhaust; e.g., typical turbochargers can lower the exhaust gas temperature by more than $100{ }^{\circ} \mathrm{C}$ [2]. The lower temperature poses a great challenge to the catalytic abatement of $\mathrm{NOx}\left(\mathrm{NO}+\mathrm{NO}_{2}\right)$ under both excess oxygen (lean feed) and low exhaust temperature. The reduction of NOx in excess oxygen must compete with oxygen reduction by available reductants which increases fuel consumption. Lower exhaust temperature leads to slower conversion rates and correspondingly lower conversion efficiencies. Meeting stricter tailpipe emission standards like Tier 3, LEV III and Euro 6 will necessitate new deNOx technologies that achieve higher lean NOx conversions, particularly in the low temperature range $\left(\sim 150\right.$ to $\left.250{ }^{\circ} \mathrm{C}\right)[2,3]$.

Commercial lean NOx abatement technologies include selective catalytic reduction of NOx with $\mathrm{NH}_{3}\left(\mathrm{NH}_{3}-\mathrm{SCR}\right)$ and $\mathrm{NOx}$ storage reduction (NSR). SCR is a more mature and implemented technology that efficiently reduces NOx to $\mathrm{N}_{2}$ over vanadium-based or transition metal exchanged zeolite catalysts with $\mathrm{NH}_{3}$ generated upstream from urea thermal hydrolysis. A minimum urea dosing temperature of $\sim 200{ }^{\circ} \mathrm{C}$ limits the 
low-temperature functionality of SCR. In contrast, NSR technology, also referred to as lean NOx trap (LNT) technology, involves cyclic operation comprising a sequential lean phase (typically 30-90 s) and much shorter rich phase (3-10 s). LNT catalyst contains noble metals (e.g., Pt, Rh) and $\mathrm{NOx}$ storage materials (e.g., $\mathrm{K}_{2} \mathrm{O}, \mathrm{BaO}$ ) supported on high surface area $\gamma-\mathrm{Al}_{2} \mathrm{O}_{3}[4,5,6]$. Ceria $\left(\mathrm{CeO}_{2}\right)$ is often added to the LNT catalyst as a promotor. The underlying process involves the combination of Pt-catalyzed $\mathrm{NO}$ oxidation to $\mathrm{NO}_{2}$ which is trapped on the storage material in the form of nitrates/nitrites during the lean phase. This is followed by reductive conversion of the stored $\mathrm{NOx}$ species to a mixture of $\mathrm{N}_{2}, \mathrm{NH}_{3}$, and $\mathrm{N}_{2} \mathrm{O}$ during the shorter rich phase [5]. Intermittent in-cylinder rich combustion or injection of fuel into the exhaust produce an exhaust containing a stoichiometric surplus of $\mathrm{CO}, \mathrm{H}_{2}$ and hydrocarbons $(\mathrm{HC})[5,6]$. The operation temperature window for LNT catalysts is relatively narrow $\left(250-400{ }^{\circ} \mathrm{C}\right)$ [7]. The low-temperature LNT performance is limited by an incomplete regeneration, as well as by low rates of NO oxidation. High-temperature performance suffers from deceased NOx storage capacity as nitrates/nitrites become thermally unstable.

Improvements are required in either SCR or NSR system to provide high NOx removal efficiency over a broad range of operating conditions encountered in practice. An intriguing yet sparsely applied concept combines the NSR and SCR technologies, based on the premise that the LNT catalyst generates $\mathrm{NH}_{3}$ for use by the SCR catalyst positioned in sequence (dual brick design) or in parallel (dual layer design) [8-11]. 
Thus, the LNT + SCR system exploits the $\mathrm{NH}_{3}$ generation capability of the LNT catalyst and the $\mathrm{NH}_{3}$ sorption and NOx reduction capability of the SCR catalyst. The combined system offers the potential of enhancing NOx conversion, reducing $\mathrm{NH}_{3}$ slip, and lowering the required precious group metal (PGM) load. The LNT + passive SCR system was commercially applied on several vehicle models such as the Mercedes E320 Blutec. [12]. In most previous LNT+SCR studies the overall NOx conversion was primarily accomplished in the LNT. Efforts have been made to improve LNT regeneration in order to achieve high $\mathrm{NH}_{3}$ yield at minimum fuel penalty $(<2 \%)$. Wittka et al. [8] proposed a novel configuration for the LNT + passive SCR system featuring the use of an out-line fuel reformer and an exhaust bypass around the LNT. In addition to the classic $\mathrm{NH}_{3}$-pathway for the combined system, Ford researchers found that non- $\mathrm{NH}_{3}$ reductants like $\mathrm{HC}$ derivatives produced from the reaction of $\mathrm{HC}$ and stored NOx during LNT regeneration, could enable additional NOx conversion by the SCR $[9,13]$.

Toyota researchers reported in recent years an interesting technology called "Di-Air" (standing for diesel NOx aftertreatment by adsorbed intermediate reductants) that achieves much higher NOx conversion over a LNT catalyst at elevated temperatures $[14,15,16]$. The unique operational feature of Di-Air is the high frequency injection of $\mathrm{HC}$ into a lean exhaust stream with cycle times shorter than $\sim 5$ s flowing continuously over a LNT catalyst. The enhanced NOx conversion performance was attributed to adsorbed, N-containing $\mathrm{HC}$ intermediates, which are generated during 
the high-frequency HC pulsing, through reaction between adsorbed NOx and partially oxidized hydrocarbons. These short-lived intermediates are readily converted through reaction with surface and/or gas phase NOx species to $\mathrm{N}_{2}$ during the lean part of the cycle. Compared to NSR, the Di-Air operation shifts the $\mathrm{N}_{2}$ formation from one that occurs primarily during the rich phase to one that primarily occurs during the lean phase. The system was demonstrated to significantly improve the deNOx performance under high-temperature and high-SV operations conditions for which conventional NSR (cycle time 0.5-2 min) performs unsatisfactorily. In a recent study our group found that fast cycling of propylene enhanced the deNOx activity of LNT catalysts even at low temperatures, albeit to a smaller extent than at high temperatures [17].

A definitive mechanism has yet to be established for the Di-Air process although progress is being made. Toyota researchers advanced a mechanism that is similar to the aforementioned "non- $\mathrm{NH}_{3}$ " pathway encountered with the LNT-SCR system. Both involve the formation of $\mathrm{HC}$ intermediates $\left(\mathrm{C}_{\mathrm{x}} \mathrm{H}_{\mathrm{y}} \mathrm{O}_{\mathrm{z}}, \mathrm{C}_{\mathrm{x}} \mathrm{H}_{\mathrm{y}} \mathrm{O}_{\mathrm{z}} \mathrm{N}_{\mathrm{t}}\right)$ through reaction of adsorbed NOx and oxygenated hydrocarbon species that accumulate on the LNT catalyst during the rich purge. Zheng et al. [18] showed that these surface HC intermediates play an important role in the low-temperature NOx conversion enhancement in the combined LNT-SCR system. Our recent preliminary study showed that a Di-Air process with high-frequency HC pulsing can benefit a combined LNT+ passive SCR system, especially at low temperatures [19]. 
The aim of this follow-up study is to gain insight into the working mechanism of rapid propylene pulsing on integrated LNT-SCR catalysts, with the objective to expand the operating temperature window of a conventional NSR system. We first demonstrate the enhanced NOx conversion by the use of high injection frequency and/or SCR top-layer. We then investigate the impacts of relevant factors, including cycle timing (NSR and Di-Air operation), exothermic heat effects, SCR catalyst types ( $\mathrm{Cu}$-zeolites and $\mathrm{Ag} / \mathrm{Al}_{2} \mathrm{O}_{3}$ ), and loadings of ceria and PGM, on the catalyst system performance in terms of catalytic activity, product distribution and catalyst durability. An overall mechanism for fast HC pulsing in both the standalone LNT and combined catalyst system is proposed. We also show how the deNOx performance may be enhanced by configuring the catalyst architecture through, layering and zoning.

\section{Experimental}

\subsection{Catalysts}

The monolithic LNT catalysts provided by BASF (Iselin, NJ) have a cell density of 400 cpsi (cells per square inch) and washcoat loading of $4.6 \mathrm{~g} / \mathrm{in}^{3}$ monolith, corresponding to a peripheral-averaged thickness of $\sim 80 \mu \mathrm{m}$. The catalyst contains $\mathrm{Pt} / \mathrm{Rh} / \mathrm{BaO} / \mathrm{CeO}_{2} / \mathrm{Al}_{2} \mathrm{O}_{3}$ with an overall PGM (precious group metal) loading of 90 $\mathrm{g} / \mathrm{ft}^{3}$ monolith, 15 wt.\% (washcoat basis) $\mathrm{BaO}$ and 34 wt. $\% \mathrm{CeO}_{2}$ on a $\gamma$-alumina support. In some experiments, a LNT with the same specifics except for no $\mathrm{CeO}_{2}$ addition was used which was also provided by BASF. Small cylindrical catalyst samples ( $\sim 55$ channels, $\mathrm{D}=0.42$ in, $\mathrm{L}=1$ in) were drilled out of a large brick. The 
in-house synthesized small-pore Cu-SAPO-34 with chabazite (CHA) framework and $\mathrm{Ag}(2 \mathrm{wt} . \%) / \mathrm{Al}_{2} \mathrm{O}_{3}$ catalyst powders were prepared via solid-state ion exchange [20] and incipient wetness impregnation methods [21], respectively. The as-prepared catalyst powder was washcoated onto the LNT monoliths by a dip-coating technique described elsewhere [22]. A uniform washcoat layer of $0.8-0.9 \mathrm{~g} / \mathrm{in}^{3}$ was deposited on top of the LNT layer creating dual-layer catalysts (LNT-SCR, LNT-Ag/ $\mathrm{Al}_{2} \mathrm{O}_{3}$ ). All catalysts were aged at $700{ }^{\circ} \mathrm{C}$ for 33 hours in air, equivalent to $160,000-\mathrm{km}$ aging, prior to bench reactor experiments [14].

\subsection{Reactor System}

A schematic of the bench-scale reactor system was provided in a previous paper [19]. The set-up comprised four major components: gas supply, tubular reactor, analytical and data acquisition systems. The flow reactor utilized synthetic exhaust gas mixtures from cylinder-supplied gases (Praxair). Gas flow rates were controlled by mass flow controllers (MKS Instruments). Water was fed by a syringe pump (ISCO Model 500D) and vaporized in a heated line. In all experiments, the total gas flow was 3000 $\mathrm{cm}^{3} / \mathrm{min}$, corresponding to a gas hourly space velocity (GHSV) of ca. $74,000 \mathrm{~h}^{-1}$ at standard conditions. The gases were pre-mixed in three separate lines; one line contained inert species $\left(\mathrm{CO}_{2}, \mathrm{H}_{2} \mathrm{O}\right.$, Ar), another the lean feed components $\left(\mathrm{NO}, \mathrm{O}_{2}\right.$, Ar), and a third the rich feed components (NO, $\left.\mathrm{O}_{2}, \mathrm{C}_{3} \mathrm{H}_{6}, \mathrm{Ar}\right)$. The monolith catalyst core sample was wrapped with Fiberfrax ${ }^{\circledR}$ ceramic paper and inserted into a quartz tube $(\mathrm{OD}=0.75$ in. $)$ positioned inside a Thermocraft ${ }^{\mathrm{TM}}$ tube furnace. Local feed gas 
and catalyst temperatures were measured using two K-Type thermocouples (Omega Engineering Inc.). One thermocouple was placed 0.5 in. upstream of the catalyst to monitor the feed temperature $\left(T_{f}\right)$, while another was positioned at the midpoint of the monolith (radial and axial) to measure the temperature at the center of the catalyst $\left(T_{c}\right)$. Note that $T_{c}$ is a dependent variable, which varied markedly during the aerobic regenerations. The outlet gas stream flowed through a heated line at ca.190 ${ }^{\circ} \mathrm{C}$ to the MultiGas 2030 FTIR (MKS Instruments), which measured concentrations of NO, $\mathrm{NO}_{2}, \mathrm{~N}_{2} \mathrm{O}, \mathrm{C}_{3} \mathrm{H}_{6}, \mathrm{NH}_{3}, \mathrm{HCHO}, \mathrm{HNCO}, \mathrm{CO}, \mathrm{CO}_{2}$ and $\mathrm{H}_{2} \mathrm{O}$.

A solenoid actuated four-way valve (Valco Inc., Micro-electric two position valve) generated the high-frequency propylene pulses via fast switching between lean and rich feeds. The lean and rich feeds were connected to the inlets of the switching valve, while one outlet of the valve was connected to the main gas line just upstream of the catalyst sample and the other to the vent. The flow rate of the inert gas in the main line was kept at $800 \mathrm{~cm}^{3} / \mathrm{min}$, lower than the $2200 \mathrm{~cm}^{3} / \mathrm{min}$ for the lean or rich reactive feed. The main purpose was to guarantee that the correct amount of reactive feed was injected during the fast switching. HC premixed in the rich line also helps avoid flow maldistribution. This was important as Toyota researchers recently pointed out that high radial uniformity of $\mathrm{HC}$ concentration was essential for Di-Air performance [23]. In order to minimize upstream axial mixing of lean and rich streams, the switching valve was placed close to the monolith catalyst $(\sim 0.6 \mathrm{~m}$ upstream), but sufficiently far to enable sufficient preheating of the feed stream. We 
found that too long a distance between the switching valve injection point and the catalyst resulted in an unacceptable level of axial mixing due to dispersion in the tubing. The axial mixing decreased NOx conversion during high frequency operation. (We did not investigate in detail this design variable in the current study so the $0.6 \mathrm{~m}$ distance may not be the optimal value.). The injection valve, thermocouples and MFCs were all controlled and monitored using LABVIEW ${ }^{\mathrm{TM}}$ software. Time delays between the feed point, reactor and the analytical equipment were accounted for in the data processing through tracer measurements.

Lean-rich cycling experiments were conducted over either the LNT only, LNT-SCR dual-layer, LNT-Ag/ $/ \mathrm{Al}_{2} \mathrm{O}_{3}$ dual-layer or LNT-SCR dual-brick catalysts. Table 1 describes the cycling conditions. Three different cycle timing protocols, 60s lean/10s rich, 30s lean/5s rich, and $6 \mathrm{~s}$ lean/1s rich, were used. The 60/10 and 30/5 timing are representative of conventional NSR operation while the $6 / 1$ is representative of high-frequency NSR (simulated Di-Air). Due to the system limitation (switching delay time, mixing design to get rectangular plug flow HC pulses) higher injection frequency could not be realized. In the Di-Air process studies of Toyota the air:fuel ratio $(\mathrm{A} / \mathrm{F})$ was varied periodically through reductant injection into a flowing lean gas. To mimic this approach, we used a high $\mathrm{O}_{2}$ concentration of $10 \%$, typical of real diesel exhaust, in the lean feed and 5\% in the rich feed. Previous studies found that a rich duty cycle (rich phase duration divided by total cycle time) of $\sim 14 \%$ achieved a high NOx conversion [24]. Hence, this value was used in all cycling experiments. The

$$
S_{N}=\frac{2\left[\mathrm{O}_{2}\right]+[\mathrm{NO}]}{9\left[\mathrm{C}_{3} \mathrm{H}_{6}\right]}
$$


stoichiometric number is the molar ratio of the oxidizing to reducing components:

$$
S_{N}=\frac{2\left[\mathrm{O}_{2}\right]+[N O]}{9\left[\mathrm{C}_{3} \mathrm{H}_{6}\right]}
$$

A $S_{N}$ value greater than unity represents a lean mixture, whereas a $S_{N}$ value less than unity represents a rich mixture. $S_{N, p}$ and $S_{N}$ denote the stoichiometric number of the feed stream during the rich pulse and the cycle-averaged value, respectively. At each temperature the final ten periodic cycles were averaged after the system reached a periodic state to determine the cycle-averaged $\mathrm{NOx}$ and $\mathrm{C}_{3} \mathrm{H}_{6}$ conversions, product selectivities and $\mathrm{T}_{\mathrm{c}}$ according to standard expressions preciously reported [17].

Prior to testing, each catalyst was pretreated by exposing it at $400{ }^{\circ} \mathrm{C}$ for $15 \mathrm{~min}$ to lean/rich 30/5s and 6/1s cycling conditions, respectively. Different pretreatment methods caused different low-temperature cycle-averaged NOx conversions with the above periodic lean/rich pretreatment superior to that following an oxidative pretreatment (i.e. $5 \% \mathrm{O}_{2}$ for $30 \mathrm{~min}$ ).

\section{Results and discussion}

\subsection{Effects of combining rapid propylene pulsing with SCR layer addition}

Fig. 1a compares the cycle-averaged NOx conversion over the standalone LNT catalyst as a function of the feed temperature for cycle times spanning 60/10s to $6 / 1 \mathrm{~s}$ for a fixed rich duty cycle (14.3\%). The dual-layer LNT-SCR catalyst at the fastest cycling (6/1s) is shown for comparison. For each of the cases the NOx conversion exhibits a rather broad maximum over a range of feed temperatures. The extent of the 
fall-off at low temperature is a sensitive function of the cycle timing and SCR top-layer.

For the longest cycle time the LNT has a NOx conversion exceeding $80 \%$ between 250 and $350{ }^{\circ} \mathrm{C}$. For feed temperatures below $225^{\circ} \mathrm{C}$ the conversion is $10-20 \%$ while at $400{ }^{\circ} \mathrm{C}$ the conversion is $\sim 70 \%$. As the cycle time is shortened to $30 / 5 \mathrm{~s}$ and $6 / 1 \mathrm{~s}$, both the low and high-temperature NOx conversions increase with the larger increase occurring at low feed temperatures $\left(\leq 250{ }^{\circ} \mathrm{C}\right)$. Finally, adding a Cu-SCR top-layer combined with fast propylene pulsing further increases the low-temperature NOx conversion. The combination of fast cycling and SCR top-layer decreases the light-off temperature by ca. $50^{\circ} \mathrm{C}$ below that of the standalone LNT with $60 / 10$ s cycle timing. For example, for a feed temperature at $225^{\circ} \mathrm{C}$, a $80 \%$ NOx conversion was achieved for the dual-layer with rapid injection, compared to $51 \%$ and $24 \%$ conversion for the standalone LNT with the fast (6/1s) and slower (30/5s) cycling, respectively. We expand on the noted low temperature enhancement by the faster cycling and addition of the SCR layer below. At high feed temperature $\left(400^{\circ} \mathrm{C}\right)$ faster cycling enhances the NOx conversion for the standalone LNT, consistent with previous studies [14, 17]. However, addition of the SCR top-layer decreases the NOx conversion. This decrease is primarily attributed to increased mass transfer resistance which limits $\mathrm{C}_{3} \mathrm{H}_{6}$ supply to the underlying LNT layer. 
The exothermic oxidation of propylene occurs during the propylene injection, and therefore non-isothermal behavior is expected. Kabin et al. [25] reported significant temperature excursion of up to $150{ }^{\circ} \mathrm{C}$ during conventional NSR using propylene as a reductant in cases when the rich feed contained up to $5 \% \mathrm{O}_{2}$. Epling et al. [26] reported an evolving and non-uniform axial temperature profile along the LNT monolith owning to the rich purge. This affected the dynamic NOx storage capacity during a cycle period. Fig. 1b shows the same cycle-averaged NOx conversion plotted as a function of the corresponding cycle-averaged $T_{c}$ (at the monolith center). A comparison of Fig. 1a and $1 \mathrm{~b}$ reveal an expansion in the temperature range due to the substantial temperature rise after ignition $\left(\mathrm{T}_{\mathrm{f}}>225{ }^{\circ} \mathrm{C}\right)$. Although $\mathrm{T}_{\mathrm{c}}$ spans a broader temperature window than $T_{f}$, the same qualitative trends in the data are apparent. One notable difference is the more significant difference in the high temperature NOx conversions for the different cycle times. These trends are in line with results reported by Bisaiji et al. [14]. It is noted that the actual temperature of the catalyst (washcoat) at the monolith midpoint is likely higher than the local gas phase temperature because of gas-to-solid heat transfer limitations.

\subsubsection{Effect of rapid propylene injection}

Detailed information on the effect of cycle timing is gotten from the instantaneous concentration and temperature profiles. Fig. 2 shows the transient effluent $\mathrm{NOx}\left(\mathrm{C}_{3} \mathrm{H}_{6}\right)$ concentration and catalyst temperature at the low feed temperature of $225^{\circ} \mathrm{C}$. The first and second columns of the figure are for the standalone LNT with $30 / 5 \mathrm{~s}$ and $6 / 1 \mathrm{~s}$ 
cycle timing, respectively. The third column shows results for the LNT-SCR dual-layer catalyst which we discuss later.

The cycle-averaged NOx conversions for the two LNT cases are $\sim 24$ and 51\%, respectively, while the corresponding cycle-averaged $\mathrm{C}_{3} \mathrm{H}_{6}$ conversions are $\sim 8$ and $40 \%$, respectively. Under the slower NSR cycling (30/5s), NOx breakthrough gradually increases during the lean period, followed by a sharp NOx spike upon switching to rich phase. This trend is typical of conventional NSR operation [5]. Generally, the inefficient low-temperature NOx conversion is a result of low rates of NO oxidation, NOx storage, and/or incomplete regeneration. Forzatti et al. [6] suggested that the slow diffusion of $\mathrm{NO}_{2}$ from $\mathrm{Pt}$ to distant $\mathrm{BaO}$ storage sites accounts for the slower uptake of NOx at the later stages of the lean phase. This is consistent with the studies of Bhatia et al. [27], Kumar et al. [28] and Shakya et al. [29] who showed through experiments and modeling that stored-NOx diffusion during both storage and release processes may limit the overall NOx conversion. In this context, proximal adsorption sites quickly saturate first then the storage slows down due to the longer diffusion distances on the surface or in the bulk of $\mathrm{BaO} / \mathrm{BaCO}_{3}$ particles. Thus, a prolonged lean phase leads to considerable NOx slip as observed (Fig. 2a). Epling et al. [30] attributed the inefficient low-temperature rich purge using hydrocarbon reductants to both slow kinetics of propylene reaction with the stored NOx and Pt site poisoning by hydrocarbon intermediates, limiting the regeneration extent. 
Lower NOx and $\mathrm{C}_{3} \mathrm{H}_{6}$ effluent concentrations are observed along with a higher and steadier catalyst temperature (see middle column of Fig. 2) upon increasing the cycling frequency (6/1s). Similar fast cycling trends were reported by Perng et al. [17]. Lietti et al. [31] suggested that at low temperatures NO may be stored in the form of nitrites and that this mechanism requires the cooperative interaction between $\mathrm{Pt}$ and nearby storage materials. This mechanism involves the following sequential steps:

$$
\begin{aligned}
& \mathrm{NO}-\mathrm{Pt}+\mathrm{O}-\mathrm{Pt}+\mathrm{BaO} \leftarrow \mathrm{BaO}\left(\mathrm{NO}_{2}\right) \\
& \mathrm{NO}-\mathrm{Pt}+\mathrm{BaO}\left(\mathrm{NO}_{2}\right) \leftarrow \rightarrow \mathrm{Ba}\left(\mathrm{NO}_{2}\right)_{2} \\
& \mathrm{BaO}+2 \mathrm{NO}+1 / 2 \mathrm{O}_{2} \leftarrow \rightarrow \mathrm{Ba}\left(\mathrm{NO}_{2}\right)_{2} \text { (overall) }
\end{aligned}
$$

This mechanism known as nitrite pathway does not require the formation of $\mathrm{NO}_{2} . \mathrm{Xu}$ et al. [32] modeled NO uptake at high temperatures and showed that for a $\mathrm{NO}+\mathrm{O}_{2}$ feed NOx storage proceeds through $\mathrm{NO}_{2}$ formation and uptake on proximal storage as well. These studies suggest that under fast cycling, NO uptake would only be possible through a fast pathway so that only kinetically accessible storage sites would be utilized. That is, fast cycling mitigates the kinetic challenge of low-temperature NOx uptake by confining NOx storage to surface $\mathrm{Ba}$ sites in close proximity to Pt via a spillover process. The fraction of $\mathrm{Ba}$ that effectively participates in the storage process is smaller than during conventional NSR operation. This diminishes the importance of NOx storage capacity that is gradually reduced with elevated temperature, thereby extending the operating window to high temperatures $(>400$ $\left.{ }^{\circ} \mathrm{C}\right)$ as shown in Fig. 1 and in the Toyota reports [14]. Perng et al. [17] showed that storage and reduction under fast cycling experiments is less sensitive to $\mathrm{CO}_{2}$. They 
argued that this is evidence for a NOx reduction mechanism that does not rely on NOx storage on $\mathrm{BaCO}_{3}$ sites that are less effective in trapping $\mathrm{NOx}$ than $\mathrm{BaO}$ or $\mathrm{Ba}(\mathrm{OH})_{2}$.

Once the proximal storage sites are saturated, a short propylene pulse is injected to purge stored NOx. Bisaiji et al. [14] proposed that the rapid HC pulsing plays a pivotal role in the Di-Air reaction pathway. HC efficiently reacts with adsorbed NOx and $\mathrm{O}_{2}$ over Pt to generate $\mathrm{N}$-containing intermediates (denoted by $\mathrm{C}_{\mathrm{x}} \mathrm{H}_{\mathrm{y}} \mathrm{O}_{\mathrm{z}} \mathrm{N}_{\mathrm{t}}$ ) which can be stabilized by the nearby basic oxide $(\mathrm{BaO})$ component and retained on the catalyst surface until the end of a sufficiently short rich phase. Such active intermediates are then either converted to $\mathrm{N}_{2}$ directly or react with adsorbed and/or gaseous NOx generating $\mathrm{N}_{2}$ during the subsequent lean period. Bisaiji et al. [16] further conducted an in operando XAFS (X-ray Adsorption Fine Structure) study to monitor the valence state of $\mathrm{Pt}$ and determined that $\mathrm{HC}$ intermediates are capable of maintaining $\mathrm{Pt}$ in a metallic state through scavenging $\mathrm{O}$ adatoms even within several seconds (up to $\sim 4 \mathrm{~s}$ ) into the subsequent lean phase. In other words, Pt is kept in a reduced state all the time under rapid $\mathrm{HC}$ pulsing. The presence of reduced Pt sites may imply a different pathway via the direct NO decomposition on metallic Pt sites as reported by Burch et al. [33], compared to Toyota's pathway involving organo-nitrate species as key intermediates. In either pathway, the initial formation of partially oxidized HC intermediate is critical. Bisaiji et al. [14] and Perng et al. [17] reported that a high injection frequency sustains the gas phase $\mathrm{O}_{2}$ at a higher level and that this 
promotes propylene oxidation, given the positive reaction order with respect to $\mathrm{O}_{2}$ for propylene oxidation. It is noted that the high ceria content (34 wt.\%) in the LNT catalyst used in the current study also acts as oxygen buffer to maintain surface oxygen concentration. The functionality of ceria for fast cycling is further discussed later. In summary, fast injection of propylene encounters relatively high-levels of both stored and gaseous $\mathrm{O}_{2}$. This enables improved utilization of the propylene reductant, evidenced by the much lower $\mathrm{C}_{3} \mathrm{H}_{6}$ breakthrough. In addition, better propylene oxidation results in higher catalyst temperature which, in turn, benefits efficient NOx storage and regeneration, especially at low temperatures.

\subsubsection{Effect of Cu-SAPO-34 top-layer}

The deposition of a Cu-SCR layer and fast cycling leads to an even higher NOx and $\mathrm{C}_{3} \mathrm{H}_{6}$ conversion. As shown in the right column of Fig. 2, the addition of a Cu-SAPO-34 top-layer to the LNT catalyst while maintaining the $6 / 1$ s cycling results in a noted drop in the NOx and $\mathrm{C}_{3} \mathrm{H}_{6}$ effluent concentrations. The cycle-averaged NOx conversion is $\sim 80 \%$, an absolute increase of $29 \%$ from the standalone LNT under fast cycling. Moreover, the resulting $\mathrm{T}_{\mathrm{c}}$ is higher by over $30{ }^{\circ} \mathrm{C}$. A previous study showed that due to the higher oxygen level and short rich duration, negligible $\mathrm{NH}_{3}$ slips from the LNT upon fast cycling over the almost entire temperature range [19]. Thus, the classic $\mathrm{NH}_{3}$-pathway cannot account for the increased NOx conversion on the dual-layer catalyst. 
An alternative mechanism for the $\mathrm{LNT}+\mathrm{SCR}$ system that does not require $\mathrm{NH}_{3}$ was advanced by Ford researchers [9, 13]. Bisaiji et al. [14] reported the detection of several stable gas phase intermediates in LNT effluent during rapid HC pulsing, including amines $\left(\mathrm{CH}_{3} \mathrm{NH}_{2}, \mathrm{C}_{2} \mathrm{H}_{5} \mathrm{NH}_{2}, \mathrm{NH}_{2} \mathrm{OH}\right)$, carboxylic acids $(\mathrm{HCOOH}$, $\left.\mathrm{CH}_{3} \mathrm{COOH}\right)$ and aldehydes $\left(\mathrm{CH}_{3} \mathrm{CHO}\right)$. In the current study, we observed both $\mathrm{HCHO}$ and HNCO in the effluent during fast cycling to the standalone LNT catalyst at a feed temperature of $225^{\circ} \mathrm{C}$. Other propene oxidation derivatives in addition to $\mathrm{HCHO}$ and HNCO are likely to exist but only $\mathrm{HCHO}$ and $\mathrm{HNCO}$ were reported due to measurement limitations. It is expected that such intermediates released from the LNT may be trapped and utilized as reductants in the SCR top-layer via a HC-SCR pathway. These species have been previously reported as NOx reductants via a HC-SCR pathway on zeolite catalysts [34-36]. For example, Peden et al. [37] reported that the partially oxidized propylene species are more active than propylene for NOx reduction over $\mathrm{Ba}-$ or $\mathrm{Na}$ - exchanged zeolite catalysts. In fact, a feed containing aldehyde species like $\mathrm{HCHO}, \mathrm{CH}_{3} \mathrm{CHO}$, etc., included in a lean NOx stream resulted in $80 \%$ NOx conversion over a BaY zeolite catalyst at $200{ }^{\circ} \mathrm{C}$ [37]. This supports our conjecture that the added SCR layer can utilize released intermediates for additional NOx reduction.

To gain further insight into the catalytic oxidation chemistry, DRIFTS (diffuse reflectance infrared Fourier transform spectroscopy) measurements were conducted to identify and monitor the evolution of surface organic intermediates over powder LNT 
and SCR catalysts. Fig. 3a-b show the temporal changes of the in situ DRIFTS spectra when exposing a NOx pre-adsorbed LNT to a feed of $0.1 \% \mathrm{C}_{3} \mathrm{H}_{6}+1 \% \mathrm{O}_{2}$ at $200{ }^{\circ} \mathrm{C}$. After a $1 \mathrm{~h}$ pre-conditioning, the catalyst was exposed to a feed containing $500 \mathrm{ppm}$ $\mathrm{NO}+5 \% \mathrm{O}_{2}$. Three intense peaks were observed at 1270,1300 and $1575 \mathrm{~cm}^{-1}$, which can be assigned to the bulk nitrates, surface nitrites and surface nitrates, respectively $[38,39]$. Upon the introduction of propylene the spectra exhibited a temporal decrease in the intensity of the surface nitrates peaks at 1300 and $1575 \mathrm{~cm}^{-1}$, and a near-simultaneous evolution of four new bands at 1650, 1680, 2190 and $2215 \mathrm{~cm}^{-1}$. Compared to the nearly constant peak at $1270 \mathrm{~cm}^{-1}$ corresponding to bulk nitrates, the dramatic decrease in the spectral intensity of the surface nitrates peak suggests that NOx stored at surfaces sites close to the $\mathrm{Pt}$ are prone to conversion at low temperatures. This corroborates our previous argument that fast cycling favors the efficient utilization of fast (proximal) NOx storages sites. The band at $1650 \mathrm{~cm}^{-1}$ is most likely a $\mathrm{C}=\mathrm{O}$ group of either surface acrylate $\left(\mathrm{R}-\mathrm{COO}^{-}\right)$or aldehydes $(\mathrm{R}-\mathrm{CHO})$ like acrolein [40]. The bands at 1680, 2190 and $2215 \mathrm{~cm}^{-1}$ are assigned to $\mathrm{C}=\mathrm{N}$ stretching vibration of acetone oxime [35], isocyanate (R-NCO) over barium [41] or cyanide species (R-CN) over alumina [42], and surface isocyanate over alumina [41], respectively. Thus, these surface species measurements together with the gas phase species $\mathrm{HNCO}$ and $\mathrm{HCHO}$, as well as the additional species reported by Toyota researchers suggest either a direct release or hydrolysis of activated surface intermediates over the LNT during the rapid HC pulsing into a lean NOx stream. 
Fig. 3c shows the temporal DRIFTS spectra when exposing a NOx pre-adsorbed SCR catalyst to a feed of $0.1 \% \mathrm{C}_{3} \mathrm{H}_{6}+1 \% \mathrm{O}_{2}$ at $200{ }^{\circ} \mathrm{C}$ in a separate experiment. The SCR powder used here is $\mathrm{Cu}-\mathrm{SSZ}-13$ provided by BASF. Its performance is comparable to our in-house synthesized Cu-SAPO-34 [20]. After feeding propylene for $5 \mathrm{~min}$, a band at $2278 \mathrm{~cm}^{-1}$ corresponding to R-CN [43] appears. Prolonged propylene exposure for $30 \mathrm{~min}$ results in a decrease in this peak intensity, accompanied with a gradual evolution of two new peaks at 2218 and $2254 \mathrm{~cm}^{-1}$ that can be assigned to R-NCO on $\mathrm{Cu}^{+}$and zeolite, respectively [44]. About $1 \mathrm{~h}$ after propylene admission, the peak for R-CN disappears and peaks for R-NCO stabilize at higher intensities. Isocyanates are well recognized as active intermediates that can rapidly hydrolyze to produce $\mathrm{NH}_{3}$ or amine to further reduce NOx [36]. The spectra clearly indicate a slow evolution of surface organic intermediates from R-CN $\left(2278 \mathrm{~cm}^{-1}\right)$ towards R-NCO (2218 and $2254 \mathrm{~cm}^{-1}$ ). Compared to nearly immediate evolution of R-NCO species on the LNT, the time taken to form R-NCO on the SCR is much longer. This suggests the formation of $\mathrm{NCO}$ may be the RDS for the HC-SCR pathway on the Cu-CHA catalysts, especially at low temperature. Thus, we speculate that the activated HC intermediates provided by the LNT facilitate the formation of R-NCO on the $\mathrm{Cu}-\mathrm{CHA}$ catalyst, thereby promoting the LNT-assisted HC-SCR reaction. This hypothesis is consistent with the non- $\mathrm{NH}_{3}$ pathway proposed by Ford researchers $[9,13]$.

\subsection{Effect of ceria in LNT layer}


Fig. 4 compares the NOx conversion as a function of feed temperature under fast cycling obtained with two dual-layer catalysts, one with the same LNT formulation having ceria and the second without ceria. The effect of ceria is marked: in its absence the cycle-averaged NOx conversion is significantly lower over the entire feed temperature range. A large number of previous studies have shown the important role of ceria in automotive emission control, including oxygen storage capacity, low-temperature NOx storage and stabilization of Pt dispersion, etc [45-47]. As suggested earlier, ceria supplies oxygen to promote the oxidation of propylene to form surface intermediates that are critical for fast-cycling performance. Yi et al. [22] reported that ceria enhanced the resistance of LNT-SCR dual-layer catalysts to thermal aging by suppressing the migration of $\mathrm{Pt}$ and $\mathrm{BaO}$ from underlying LNT to the top SCR layer. Recently, Kapteijn et al. [48] argued that ceria might provide active sites for NOx reduction under fast cycling conditions. Using Temporal Analysis of Products (TAP) they showed that propylene reduces the ceria surface layer from $\mathrm{Ce}^{4+}$ to $\mathrm{Ce}^{3+}$, thereby creating surface layer oxygen vacancies that are active for $\mathrm{NO}$ decomposition to $\mathrm{N}_{2}$. It is speculated that $\mathrm{HC}$ surface species act to maintain the reduced state of surface ceria rather than directly reacting with surface NOx species [48]. Further study is needed, especially operando monitoring of ceria valence state under realistic Di-Air condition and interaction of ceria with $\mathrm{Pt}$ and basic storage material. At any rate, ceria certainly plays a crucial role in the activity and durability of LNT and dual-layer catalysts under fast cycling operation. 


\subsection{Effect of top-layer material}

Based on our hypothesis that the added SCR top-layer utilizes hydrocarbon intermediates generated and released from the underlying LNT layer via a HC-based SCR pathway, we compared the performance of three top-layer materials: $\mathrm{Cu}-\mathrm{SAPO}-34, \gamma-\mathrm{Al}_{2} \mathrm{O}_{3}$ and $\mathrm{Ag} / \mathrm{Al}_{2} \mathrm{O}_{3}$. The $\mathrm{Cu}$-exchanged aluminosilico phosphate SAPO-34 is of interest because it and the related Cu-exchanged SSZ-13 zeolite have very high $\mathrm{NH}_{3}$-based SCR activity. $\mathrm{Ag} / \mathrm{Al}_{2} \mathrm{O}_{3}$ is of interest because it is a known effective HC-SCR catalyst $[21,49]$. The use of unimpregnated $\gamma-\mathrm{Al}_{2} \mathrm{O}_{3}$ is intended to check whether the NOx conversion enhancement might be the result of storage and transport effects only. Fig. 5a compares the cycle-averaged NOx conversions of dual-layer catalysts with the three top-layer materials. The data show that the $\mathrm{Cu}-\mathrm{SAPO}-34$ top-layer has the highest NOx conversion at feed temperatures below $300{ }^{\circ} \mathrm{C}$ while the $\gamma-\mathrm{Al}_{2} \mathrm{O}_{3}$ top-layer has the highest $\mathrm{NOx}$ conversion at high temperatures $\left(\geq 350{ }^{\circ} \mathrm{C}\right)$ among all the samples.

We consider first the $\gamma-\mathrm{Al}_{2} \mathrm{O}_{3}$ results. The lower NOx conversion obtained with the $\gamma-\mathrm{Al}_{2} \mathrm{O}_{3}$ top-layer for $\mathrm{T}_{\mathrm{f}} \leq 300{ }^{\circ} \mathrm{C}$ compared to $\mathrm{Cu}$-SAPO-34 top-layer is undoubtedly a result of the lower HC-SCR activity. The added $\gamma-\mathrm{Al}_{2} \mathrm{O}_{3}$ top-layer slightly enhances the low-temperature NOx conversion of LNT. This follows from the study of Panov et al. [37] who reported that $\gamma-\mathrm{Al}_{2} \mathrm{O}_{3}$ is able to catalyze the reduction of NOx by aldehydes, even though less effectively than metal-exchanged zeolite catalysts. This probably in part accounts for the minimal enhancement. In contrast, its higher 
high-temperature NOx conversion is attributed to its lower propylene oxidation activity. This enables more propylene to access to the underlying LNT layer.

The results obtained with the $\mathrm{Ag} / \gamma-\mathrm{Al}_{2} \mathrm{O}_{3}$ top-layer are somewhat surprising and would appear to contradict the explanations just provided for the selection of $\gamma-\mathrm{Al}_{2} \mathrm{O}_{3}$ top-layer. A dramatic performance decline was observed for the dual-layer LNT-Ag/ $\mathrm{Al}_{2} \mathrm{O}_{3}$ catalyst spanning the entire temperature range. $\mathrm{Ag} / \mathrm{Al}_{2} \mathrm{O}_{3}$ is generally regarded as an effective HC-SCR catalyst so one would expect NOx reduction chemistry to occur in the top-layer. Rather, it appears that there is significant negative interaction between $\mathrm{Ag} / \mathrm{Al}_{2} \mathrm{O}_{3}$ and LNT layers, apparently from the migration of $\mathrm{Ag}$ ions to the LNT base layer. To prove this conjecture, Fig. 5b shows the steady-state propylene oxidation light-off for the standalone LNT, LNT- $\mathrm{Al}_{2} \mathrm{O}_{3}$ and LNT-Ag/ $/ \mathrm{Al}_{2} \mathrm{O}_{3}$ dual-layer catalysts. While the LNT and LNT- $\mathrm{Al}_{2} \mathrm{O}_{3}$ catalysts have similar light-off results, the presence of $\mathrm{Ag}$ in the top-layer significantly inhibits the propylene oxidation as evidenced by the increase in the light-off temperature by almost $100{ }^{\circ} \mathrm{C}$. This suggests the poisoning effect of $\mathrm{Ag}$ on LNT catalyst, probably due to $\mathrm{Ag}$ migration to underlying LNT layer and block Pt sites, especially after high-temperature thermal aging. Further catalyst characterization is needed to verify the deactivation mechanism and will be reported elsewhere.

\section{$3.4 \mathrm{~N}_{2} \mathrm{O}$ yield and selectivity}


One of the challenges with conventional NSR operation is the relatively high levels of $\mathrm{N}_{2} \mathrm{O}$ generated at low to intermediate temperatures, especially compared to $\mathrm{NH}_{3}$-based SCR on metal-exchanged zeolites. $\mathrm{N}_{2} \mathrm{O}$ is relatively stable in the atmosphere and is a potent greenhouse gas with a global warming potential $\sim 300$ times that of $\mathrm{CO}_{2}$. The recently enacted US EPA 2017-25 greenhouse gas regulations will require the reduction of $\mathrm{N}_{2} \mathrm{O}$ from $\mathrm{LD}$ and $\mathrm{HD}$ vehicles [1]. Fig. 6 shows the $\mathrm{N}_{2} \mathrm{O}$ selectivity and yield under both conventional and fast cycling on both single-layer LNT and dual-layer catalysts. For the standalone LNT, the use of fast cycling increases the $\mathrm{N}_{2} \mathrm{O}$ selectivity and yield. These data are consistent with the earlier findings by Perng et al. [17]. Interestingly, the addition of the SCR top-layer lowers the $\mathrm{N}_{2} \mathrm{O}$ selectivity under fast cycling. This is probably due to lower $\mathrm{N}_{2} \mathrm{O}$ selectivity for NOx reduction by SCR than LNT catalysts. This encouraging result provides additional incentive for the proposed fast cycling technology. However, the highest $\mathrm{N}_{2} \mathrm{O}$ yield below $225^{\circ} \mathrm{C}$ of ca. $15 \%$ was observed for the dual-layer catalyst, due to the highest NOx conversion in this temperature range. Efforts still need to be made to further reduce the $\mathrm{N}_{2} \mathrm{O}$ formation.

\subsection{Working mechanism of rapid propylene pulsing}

To this point we have studied the effects of operating conditions (cycling frequency), catalyst design (top-layer material, LNT ceria content) and reaction phenomena (reaction exotherm, $\mathrm{HC}$ intermediates) to elucidate the performance of dual-layer catalysts under fast propylene pulsing. In contrast to conventional LNT+SCR system, 
$\mathrm{NH}_{3}$ is not a primary reductant of NOx reduction in the SCR component. Here we describe a likely mechanism spanning the complete cycle.

A schematic of the proposed cyclic mechanism is shown in Fig. 7. The high-frequency pulse of propylene into the lean feed facilitates the generation of surface hydrocarbon intermediates on the LNT by the partial oxidation of propylene, both by surface NOx and oxygen. These intermediates may desorb or accumulate. The oxidation process is enhanced by ceria, possibly through the spillover of oxygen to the precious metal crystallites. As discussed earlier, direct NO decomposition on reduced metal sites is another potential route for $\mathrm{N}_{2}$ and $\mathrm{N}_{2} \mathrm{O}$ formation. The complex set of surface catalyzed reactions generate organic oxygenates and nitrogenates which may react with $\mathrm{NO}$, selectively producing $\mathrm{N}_{2}$ and a lesser amount of byproduct $\mathrm{N}_{2} \mathrm{O}$. A key feature of this mechanism is the cycle timing. If the sustained supply of injected propylene, alternated with a lean feed, is accomplished at a sufficient frequency, then the desired HC-based SCR and/or NO decomposition may occur before the desorption of these intermediates, without the accumulation of surface nitrites and nitrates, and the production of deep reduction product $\mathrm{NH}_{3}$.

The role of the SCR top-layer is to trap partially oxygenated species that desorb from the LNT layer, enabling further production of $\mathrm{N}_{2}$ through HC-SCR pathway. That a moderate level of additional NOx reduction occurs even with a $\gamma-\mathrm{Al}_{2} \mathrm{O}_{3}$ top-layer suggests that the conversion of the intermediates is fast. Perhaps the elevated 
temperature caused by the propylene oxidation enhances the reaction rates. The coupled chemical and thermal effects enhance the low-temperature NOx conversion over that of the standalone LNT. Clearly, this proposed mechanism should be subjected to further validation with targeted experiments and modeling.

\subsection{Effects of catalyst configuration and zoning}

The intriguing behavior of the dual-layer catalysts under rapid periodic switching invites a study of the potential for alternative designs with improved performance. To illustrate, Fig. 8a compares the cycle-averaged NOx conversion under fast cycling operation using the LNT, LNT-SCR dual-layer or LNT-SCR dual-brick catalyst. For a meaningful comparison, the SCR brick had the same composition as the SCR used in the dual-layer catalyst but had a higher washcoat loading $\left(2.4 \mathrm{~g} / \mathrm{in}^{3}\right)$ than the dual-layer catalyst $\left(0.9 \mathrm{~g} / \mathrm{in}^{3}\right)$.

The comparison study reveals that the best low-temperature deNOx performance is achieved with a dual-layer catalyst, followed by the dual-brick, and then the standalone LNT. These data strongly suggest that the close proximity of the LNT and SCR is needed to fully exploit the HC-SCR NOx reduction mechanism. On the other hand, the high-temperature deNOx performance is negatively impacted by the addition of the SCR top-layer. This is likely attributed to the diffusion limitation contributed by the top-layer that limits the propylene supply to the underlying LNT layer, combined with unselective propylene oxidation in the SCR top-layer. This 
behavior was encountered in earlier dual-layer LNT-SCR studies by Zheng et al. [18] and Shakya et al. [50] and was also encountered in dual-layer ammonia slip catalysts as reported by Shrestha et al. [51].

The conversion decline at high temperatures may be lessened by utilizing a combination of SCR layering and zoning. The idea is to move a fraction of the upstream SCR top-layer downstream, giving a hybrid architecture that strikes a better balance between low- and high-temperature NOx removal (Fig. 8b). This follows a similar approach taken by Zheng et al. [10] for a conventional LNT-SCR. Because SCR zoning minimizes the detrimental impact of SCR-layer on the LNT at high temperatures while sustains the low-temperature enhancement. A detailed study of the SCR zoning effect can be found in [10].

Fast light-off of hydrocarbon oxidation to generate intermediates determines the low-temperature deNOx performance. Many previous studies have demonstrated that PGM zoning enables a good compromise between fast light-off and minimal PMG load needed. To this end, we investigated the impact of potentially reducing the overall PGM loading by appropriately reconfiguring the catalyst architecture. Fig. 9a shows that increasing the PGM loading from 90 to $120 \mathrm{~g} / \mathrm{ft}^{3}$ in the dual-layer catalysts decreases the light-off temperature to a feed temperature as low as $\sim 175{ }^{\circ} \mathrm{C}$. In practice, a low PGM loading is desired as it lowers the catalyst cost. Fig. 9b shows that the performance of zoned dual-layer catalyst with 25\% lower PGM loading, LNT 
(0.5 in. $\left.4.6 \mathrm{~g} / \mathrm{in}^{3}\right)+$ LNT-SCR (0.5 in., $2.3 \mathrm{~g} / \mathrm{in}^{3}$ for LNT and $0.9 \mathrm{~g} / \mathrm{in}^{3}$ for SCR washcoat), is comparable to that of LNT alone with higher PGM load. Given the high axial temperature gradient existed along the LNT monolith, a high upstream PGM loading enables fast light-off and a low downstream loading decreases the PGM load while providing good warm-up performance.

\section{Conclusions}

High frequency propylene pulsing of LNT or dual-layer LNT-SCR catalysts under lean conditions can enhance low-temperature deNOx efficiency and expand the operating temperature windows of a conventional NSR system. The main findings of this study are:

- High-frequency propylene pulsing expands the operating temperature window of a conventional NSR system in both the low and high-temperature regions.

- The combination of rapid propylene pulsing and the dual-layer catalyst increased low-temperature $\mathrm{NOx}$ and $\mathrm{C}_{3} \mathrm{H}_{6}$ conversions. This may be useful for advanced fuel-efficient engines with low exhaust temperatures.

- $\mathrm{HC}$ intermediates generated over the LNT can either directly react with NOx or act as oxygen scavenger to maintain $\mathrm{Pt}$ at reduced states for direct NO decomposition.

- Under fast cycling partially oxidized HC intermediates should be the primary NOx reductants for $\mathrm{SCR}$, in contrast to classic $\mathrm{NH}_{3}$-pathway. The evolution of isocyanates is considered as the RDS of HC-SCR over Cu-zeolite catalysts. 
The activated HC intermediates provided by the underlying LNT may facilitate isocyanates formation, thus promoting LNT-assisted HC-SCR pathway.

- A top-layer of $\mathrm{Cu}-\mathrm{SAPO}-34$ is beneficial while $\mathrm{Ag} / \mathrm{Al}_{2} \mathrm{O}_{3}$ is detrimental.

- Ceria plays a crucial role in the activity, durability and likely reaction pathway of LNT and dual-layer catalysts under fast cycling operation.

- Optimization of catalyst configuration (i.e., zoning of SCR and PGM) can improve system performance and decrease the catalyst price.

Studies of the impact of different HC species and higher injection frequency on the performance of both LNT alone and combined LNT-SCR catalysts are currently being conducted. Preliminary results shows the type of $\mathrm{HC}$ species is critical for low-temperature enhancement. Light olefins, which have a relatively low light-off oxidation temperature and stronger affinity to $\mathrm{Pt}$, are preferred. Propane that weakly adsorbs on $\mathrm{Pt}$ and has a higher light-off temperature, limit the performance enhancement by fast cycling and SCR-layer addition. HC mixture of short- and long-chain alkane and alkene may benefit from fast cycling operation. The results of this effort will be reported in a future study.

\section{Acknowledgement}

This study was funded by grants from the U.S. DOE National Energy Technology Laboratory as part of the Vehicles Technologies Program DOE-NETL 
(DE-EE0000205) and National Science Foundation CBET 1258688. We thank Dr.

Bill Epling for use of the DRIFTS instrument.

\section{References}

[1] T. Johnson, SAE Int. J. Engines 7 (2014) 1207-1227.

[2] M. Zammit, C.L. DiMaggio, C.H. Kim, C. Lambert, G.G. Muntean, C.H. Peden,

J.E. Parks, K. Howden, US Drive Report, Southfield, MI (2013).

[3] G.D. Neely, J.V. Sarlashkar, D. Mehta, SAE Int. J. Engines 6 (2013) 1009-1020.

[4] F. Posada, A. Bandivadekar, J. German, SAE Tech. Paper 2013-01-0539 (2013).

[5] W.S. Epling, L.E. Campbell, A. Yezerets, N.W. Currier, J.E. Parks, Catal. Rev. 46 (2004) 163-245.

[6] P. Forzatti, L. Lietti, L. Castoldi, Catal. Lett. 145 (2015) 483-504.

[7] Y. Matsuo, S. Ishimaru, M. Amano, N. Komatsu, S. Aoyagi, H. Dan, T. Endo, Y. Matsuzono, T. Ito, M. Nagata, SAE Tech. Paper 2013-01-0536 (2013).

[8] T. Wittka, B. Holderbaum, P. Dittmann, S. Pischinger, Emiss. Control Sci. Technol. 1 (2015) 167-182.

[9] L. Xu, R. McCabe, M. Dearth, W. Ruona, SAE Int. J. Fuels Lubr. 3 (2010) 37-49. [10]Y. Zheng, Y. Liu, M.P. Harold, D. Luss, Appl. Catal. B: Environ. 148 (2014) 311-321.

[11]T. Morita, N. Suzuki, N. Satoh, K. Wada, H. Ohno, SAE Tech. Paper 2007-01-0239 (2007).

[12]N. Waldbuesser, J. Guenther, H. Hoffmann, O. Erlenmayer, F. Duvinage, C. Enderle, J. Schommers, D. Waeller, SAE Tech. Paper 2010-01-1172 (2010).

[13]L. Xu, R.W. McCabe, Catal. Today 184 (2012) 83-94.

[14]Y. Bisaiji, K. Yoshida, M. Inoue, K. Umemoto, T. Fukuma, SAE Int. J. Fuels Lubr. 5 (2011) 380-388.

[15]M. Inoue, Y. Bisaiji, K. Yoshida, N. Takagi, T. Fukuma, Top. Catal. 56 (2013) 3-6.

[16]Y. Bisaiji, K. Yoshida, M. Inoue, N. Takagi, T. Fukuma, SAE Int. J. Fuels Lubr. 5 (2012) 1310-1316.

[17]C.C. Perng, V.G. Easterling, M.P. Harold, Catal. Today 231 (2014) 125-134.

[18] Y. Zheng, D. Luss, M.P. Harold, SAE Int. J. Engines 7 (2014) 1280-1289.

[19] Y. Zheng, M. Li, M. Harold, D. Luss, SAE Int. J. Engines 8 (2015).

[20]D. Wang, F. Gao, C.H. Peden, J. Li, K. Kamasamudram, W.S. Epling, ChemCatChem 6 (2014) 1579-1583.

[21]S. Satokawa, J. Shibata, K.-i. Shimizu, A. Satsuma, T. Hattori, Appl. Catal. B: Environ. 42 (2003) 179-186.

[22]Y. Liu, Y. Zheng, M.P. Harold, D. Luss, Appl. Catal. B: Environ. 132-133 (2013) 293-303.

[23]T. Uenishi, K. Umemoto, K. Yoshida, T. Itoh, T. Fukuma, Int. J. Automotive Eng. 5 (2014) 115-120. 
[24]R.L. Muncrief, K.S. Kabin, M.P. Harold, AIChE J. 50 (2004) 2526-2540.

[25] K.S. Kabin, R.L. Muncrief, M.P. Harold, Catal. Today 96 (2004) 79-89.

[26]W.S. Epling, A. Yezerets, N.W. Currier, Catal. Lett. 110 (2006) 143-148.

[27]D. Bhatia, R.D. Clayton, M.P. Harold, V. Balakotaiah, Catal. Today 147 (2009)

S250-S256.

[28] A. Kumar, M.P. Harold, V. Balakotaiah, J. Catal. 270 (2010) 214-223.

[29]B.M. Shakya, M.P. Harold, V. Balakotaiah, Chem. Eng. J. 230 (2013) 584-594.

[30]M. Al-Harbi, D. Radtke, W.S. Epling, Appl. Catal. B: Environ. 96 (2010) 524-532.

[31]L. Lietti, M. Daturi, V. Blasin - Aube, G. Ghiotti, F. Prinetto, P. Forzatti, ChemCatChem 4 (2012) 55-58.

[32] J. Xu, M.P. Harold, V. Balakotaiah, Appl. Catal. B: Environ. 104 (2011) 305-315.

[33]R. Burch, J. Breen, F. Meunier, Appl. Catal. B: Environ. 39 (2002) 283-303.

[34] Y. Zheng, M.P. Harold, D. Luss, Effects of CO, $\mathrm{H}_{2}$ and $\mathrm{C}_{3} \mathrm{H}_{6}$ on Cu-SSZ-13

catalyzed $\mathrm{NH}_{3}$-SCR, Catal. Today, 2015.

[35]H.-Y. Chen, T. Voskoboinikov, W. Sachtler, Catal. Today 54 (1999) 483-494.

[36]O. Gorce, F. Baudin, C. Thomas, P. Da Costa, G. Djéga-Mariadassou, Appl.

Catal. B: Environ. 54 (2004) 69-84.

[37]A.G. Panov, R.G. Tonkyn, M.L. Balmer, C.H. Peden, A. Malkin, J. Hoard, Selective reduction of NOx in oxygen rich environments with plasma-assisted catalysis: the role of plasma and reactive intermediates, SAE Technical Paper, 2001. [38]C. Sedlmair, K. Seshan, A. Jentys, J. Lercher, J. Catal. 214 (2003) 308-316.

[39]T. Szailer, J. Kwak, D. Kim, J. Hanson, C. Peden, J. Szanyi, J. Catal. 239 (2006) 51-64.

[40]J.-Y. Luo, H. Oh, C. Henry, W. Epling, Appl. Catal. B: Environ. 123 (2012) 296-305.

[41]H. Abdulhamid, J. Dawody, E. Fridell, M. Skoglundh, J. Catal. 244 (2006)

169-182.

[42] M. Huuhtanen, T. Kolli, T. Maunula, R.L. Keiski, Catal. Today 75 (2002) 379-384.

[43]A. Pelmenschikov, R. Van Santen, J. Janchen, E. Meijer, J. Phys. Chem. 97 (1993) 11071-11074.

[44]F. Solymosi, T. Bansagi, J. Catal. 156 (1995) 75-84.

[45]R.J. Gorte, AIChE J. 56 (2010) 1126-1135.

[46]J.-Y. Luo, W.S. Epling, G. Qi, W. Li, Catal. Lett. 142 (2012) 946-958.

[47]M. Yang, Y. Li, J. Wang, M. Shen, J. Catal. 271 (2010) 228-238.

[48] Y. Wang, J.P.d. Boer, F. Kapteijn, M. Makkee, The Role of Ceria in NOx

Reduction By Hydrocarbons and the Possible Reaction Pathway, 24th North American Catalysis Society Meeting, 2015.

[49]S. Tamm, H.H. Ingelsten, A.E. Palmqvist, J. Catal. 255 (2008) 304-312.

[50]B.M. Shakya, M.P. Harold, V. Balakotaiah, Chem. Eng. J. 237 (2014) 109-122.

[51]S. Shrestha, M.P. Harold, K. Kamasamudram, Chem. Eng. J. 278 (2015) 24-35. 
Fig. 1. Cycle-averaged NOx as a function of (a) feed temperature and (b) catalyst temperature (temperature at the center of monolith) for LNT alone and dual-layer catalysts with different cycle times.

Fig. 2. Effluent $\mathrm{NOx} / \mathrm{C}_{3} \mathrm{H}_{6}$ concentration and catalyst temperature for a set of cycling experiments at $225{ }^{\circ} \mathrm{C}$ feed temperature over LNT and dual-layer catalysts.

Fig. 3. Temporal DRIFTS spectra over (a-b) LNT and (c) SCR catalyst taken at $200{ }^{\circ} \mathrm{C}$ after a $1 \mathrm{~h}$ pre-conditioning by $500 \mathrm{ppm} \mathrm{NO}+5 \% \mathrm{O}_{2}$ and purge with $\mathrm{He}(\mathrm{a})$, subsequently exposed to a flow of $0.1 \% \mathrm{C}_{3} \mathrm{H}_{6}+1 \% \mathrm{O}_{2}$.

Fig. 4. Cycle-averaged NOx as a function of feed temperature for dual-layer catalysts with and without ceria under fast cycling.

Fig. 5. (a) Cycle-averaged NOx conversions as a function of feed temperature under fast cycling for LNT alone and dual-layer catalysts with either $\mathrm{Cu}-\mathrm{SAPO}-34$ or $\gamma-\mathrm{Al}_{2} \mathrm{O}_{3}$ or $\mathrm{Ag} / \mathrm{Al}_{2} \mathrm{O}_{3}$. (b) Propene oxidation over LNT, LNT- $\mathrm{Al}_{2} \mathrm{O}_{3}$ and LNT-Ag/Al2O3 catalysts (1111ppm $\mathrm{C}_{3} \mathrm{H}_{6}, 1 \% \mathrm{O}_{2}, 3.5 \% \mathrm{H}_{2} \mathrm{O}, 5 \% \mathrm{CO}_{2}$ ).

Fig. 6. $\mathrm{N}_{2} \mathrm{O}$ selectivity (a) and yield (b) as a function of feed temperature for LNT alone and dual-layer catalysts with different cycle times.

Fig. 7. Working mechanism for fast propylene pulsing over dual-layer catalyst.

Fig. 8. Cycle-averaged NOx as a function of feed temperature for LNT, dual-layer plus either (a) dual-brick or (b) zoned dual-layer catalysts under fast cycling.

Fig. 9. Cycle-averaged NOx as a function of feed temperature by LNT (4.6 g/in washcoat with PGM 90 g/ft ${ }^{3}$ ), LNT-SCR dual-layer (PGM 90 g/ $\mathrm{ft}^{3}$, SCR 0.9 g/in ${ }^{3}$ ) 
plus either (a) dual-layer with higher PGM load $\left(120 \mathrm{~g} / \mathrm{ft}^{3}\right)$ or (b) zoned dual-layer comprised of $0.5^{\prime \prime}$ LNT $\left(4.6 \mathrm{~g} / \mathrm{in}^{3}\right.$ washcoat with PGM $\left.90 \mathrm{~g} / \mathrm{ft}^{3}\right)$ and 0.5 ', dual-layer LNT $\left(2.3 \mathrm{~g} / \mathrm{in}^{3}\right) / \mathrm{SCR}\left(1.6 \mathrm{~g} / \mathrm{in}^{3}\right)$ with lower PGM load $\left(45 \mathrm{~g} / \mathrm{ft}^{3}\right)$. 


\section{Table 1}

Gas condition for baseline cycling test

\begin{tabular}{lll}
\hline $\mathrm{Gas}$ & Lean & Rich \\
\hline $\mathrm{NO}$ & $300 \mathrm{ppm}$ & $300 \mathrm{ppm}$ \\
$\mathrm{C}_{3} \mathrm{H}_{6}$ & - & $1.8 \%$ \\
$\mathrm{O}_{2}$ & $10 \%$ & $5 \%$ \\
$\mathrm{CO}_{2}$ & $5 \%$ & $5 \%$ \\
$\mathrm{H}_{2} \mathrm{O}$ & $3.5 \%$ & $3.5 \%$ \\
\hline
\end{tabular}


Fig. 1
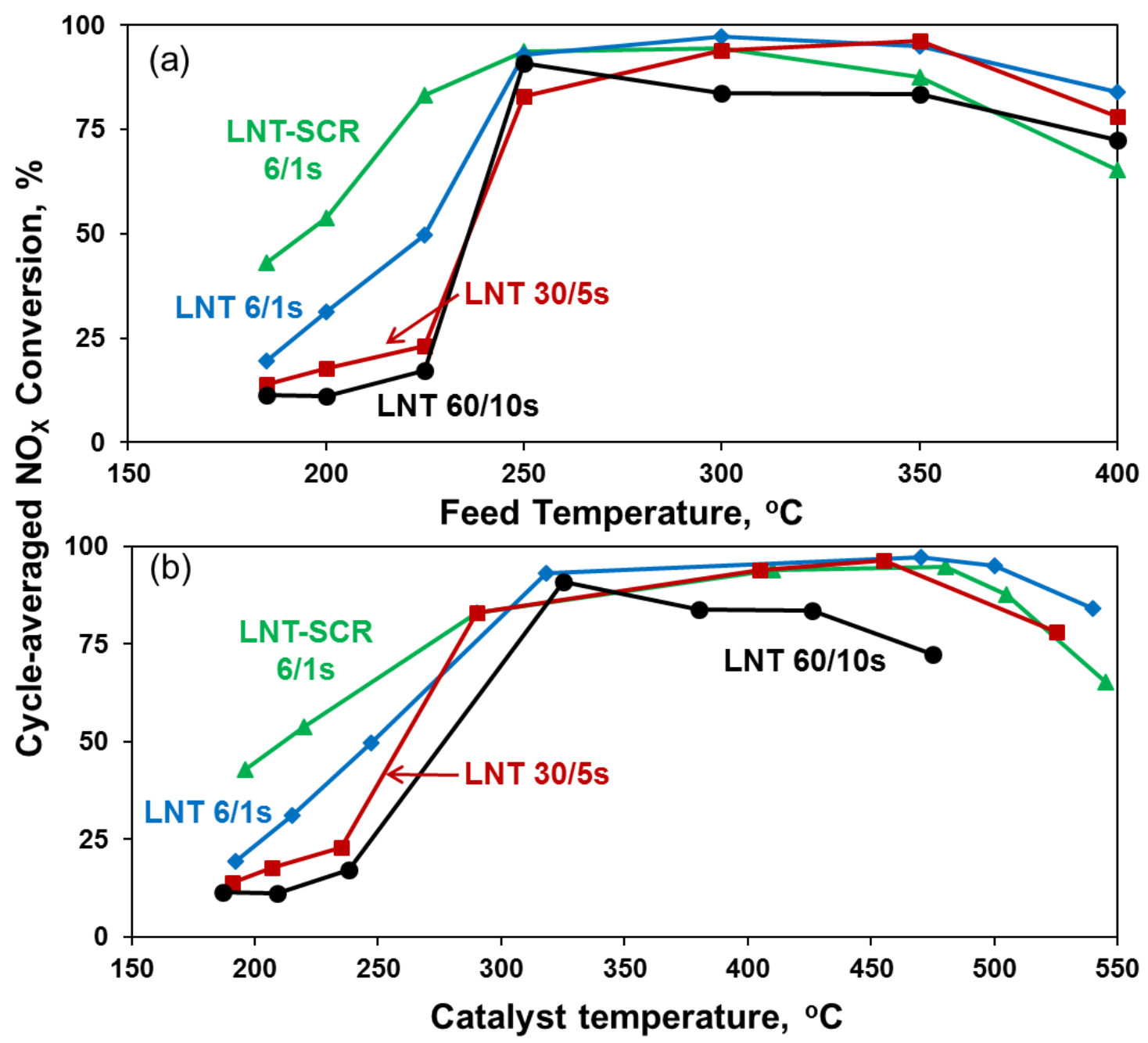
Fig. 2

a) LNT $30 / 5 \mathrm{~s}$
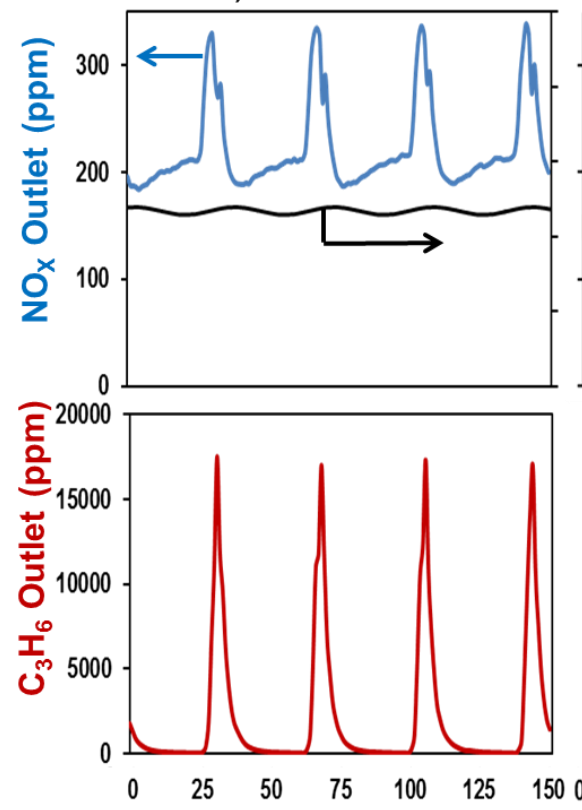

b) LNT $6 / 1 \mathrm{~s}$
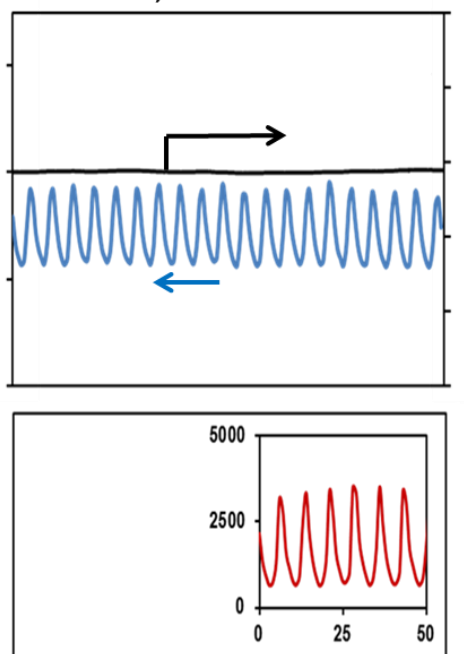

WWWWWOWWWW c) Dual-Layer $6 / 1 \mathrm{~s}$
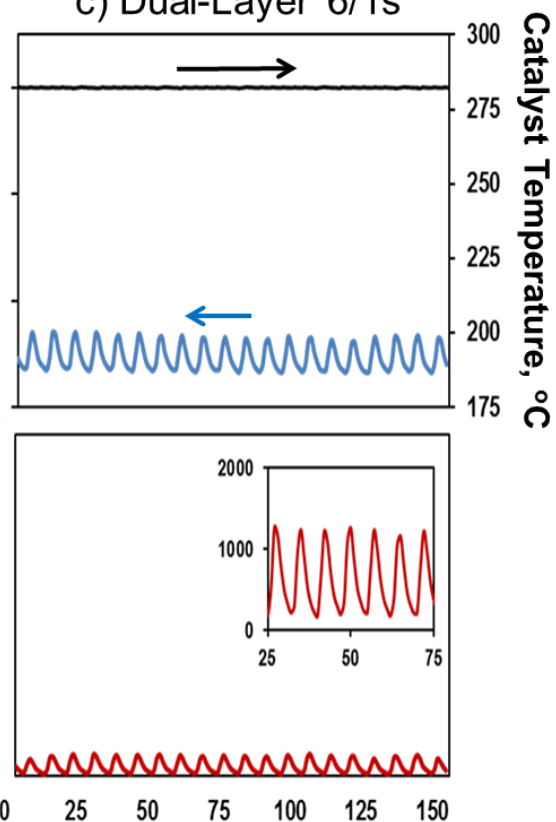

Time (s) 
Fig. 3
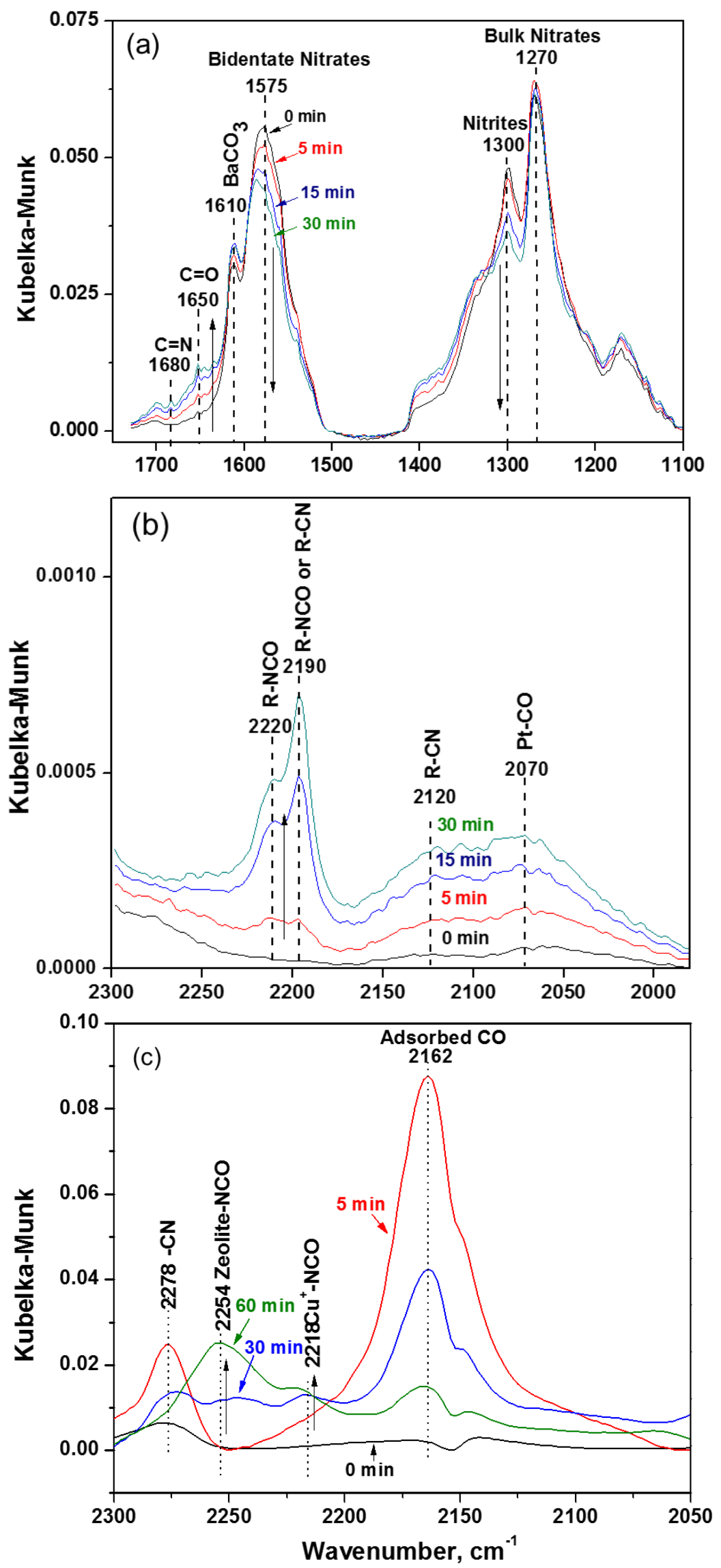
Fig. 4

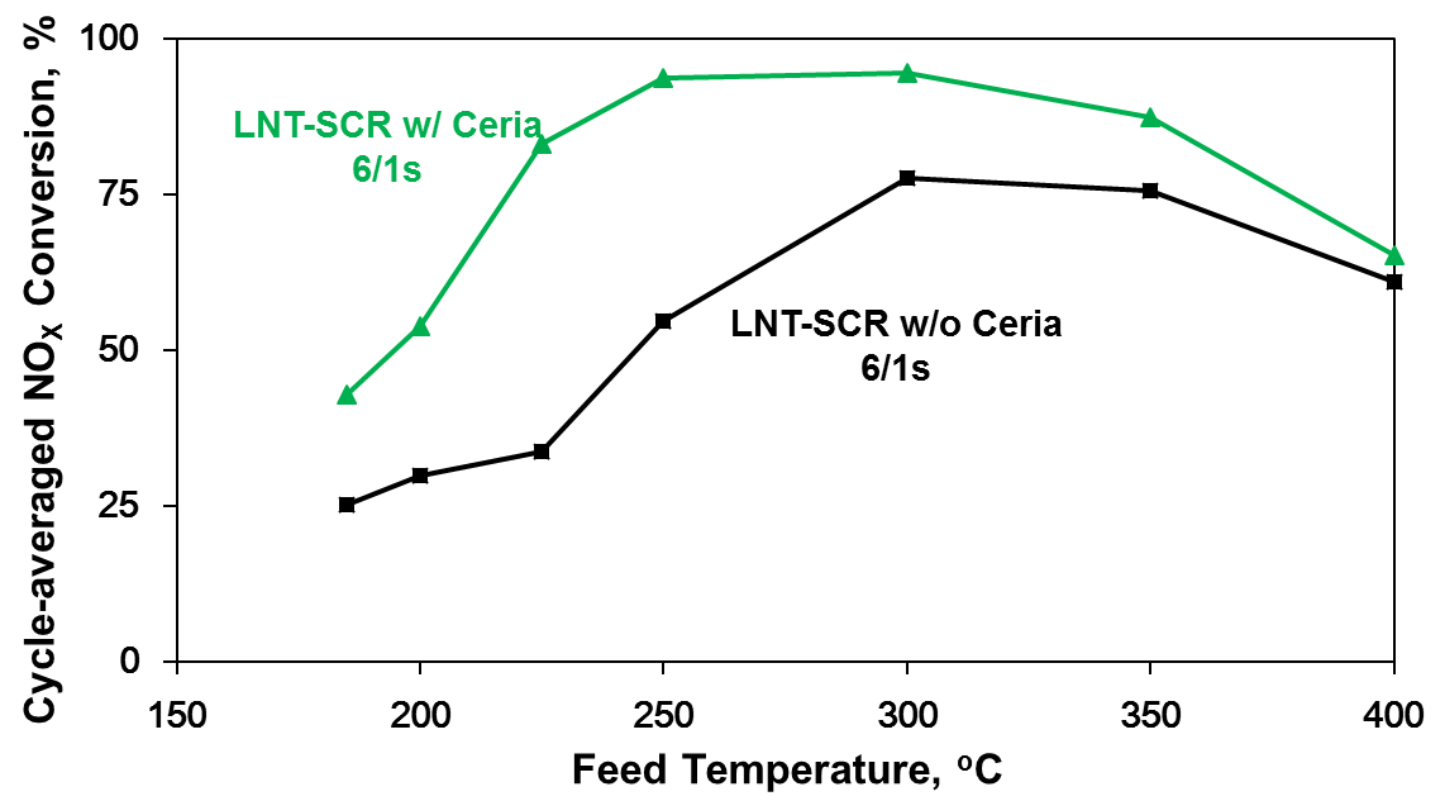


Fig. 5
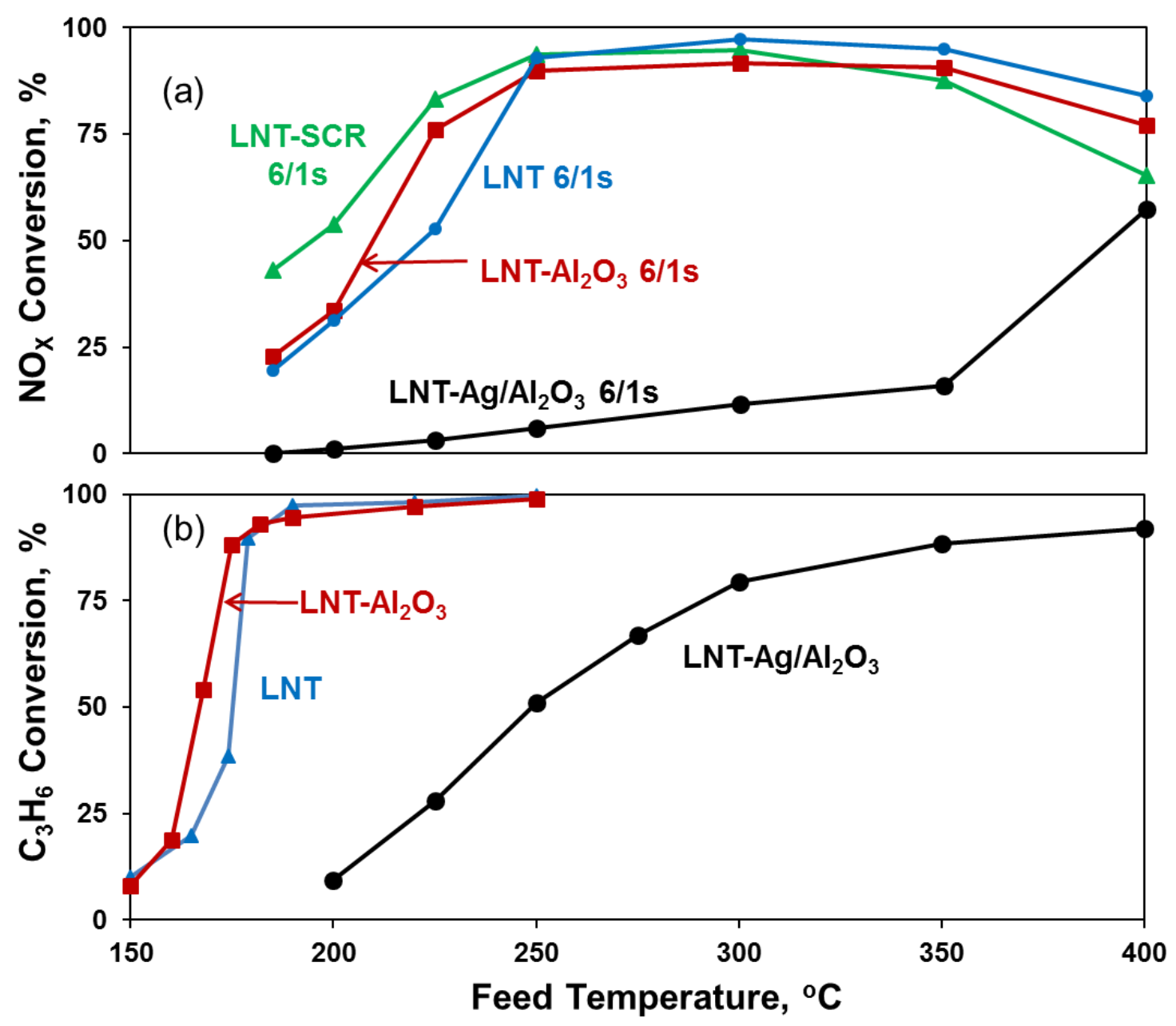
Fig. 6
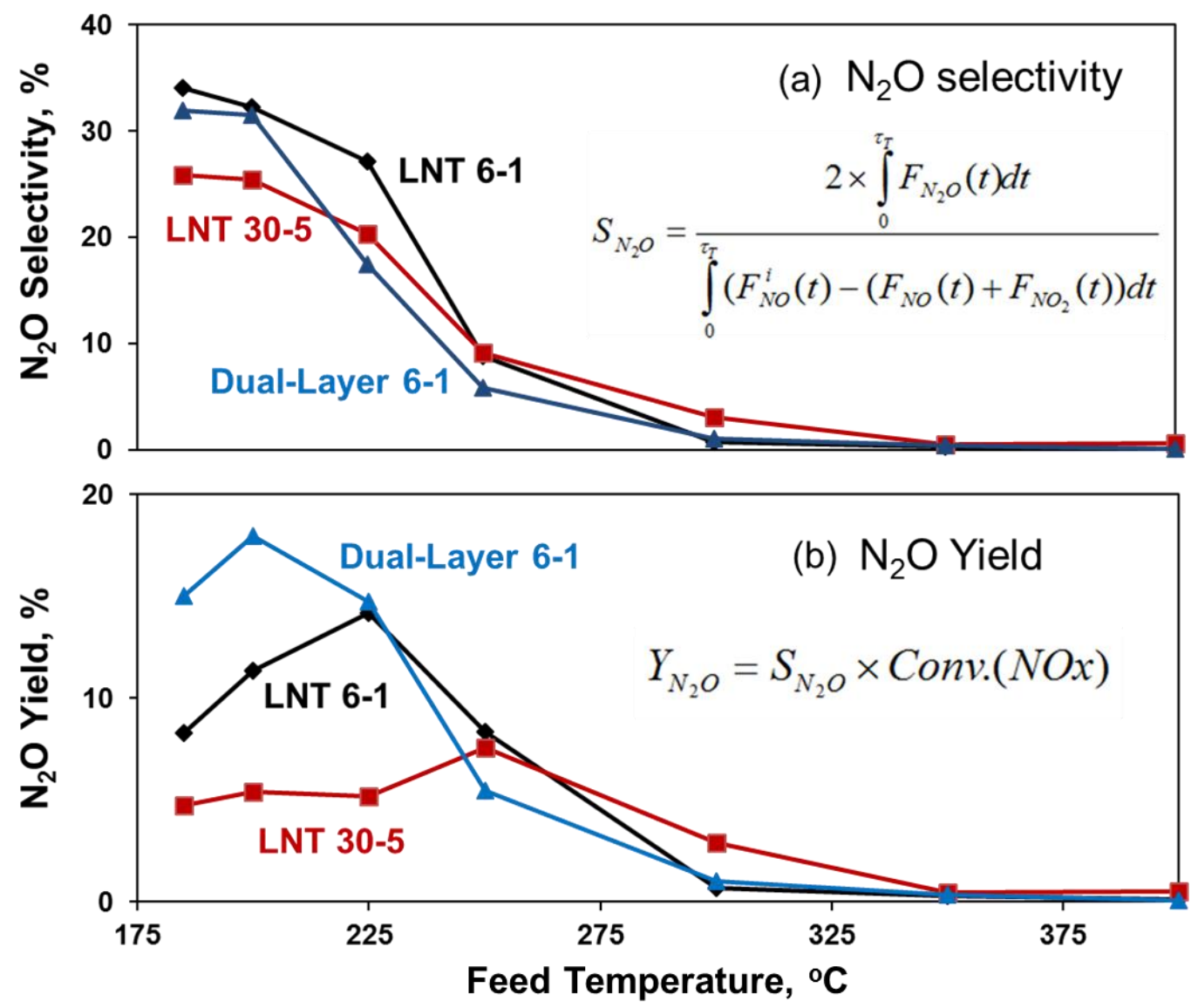
Fig. 7

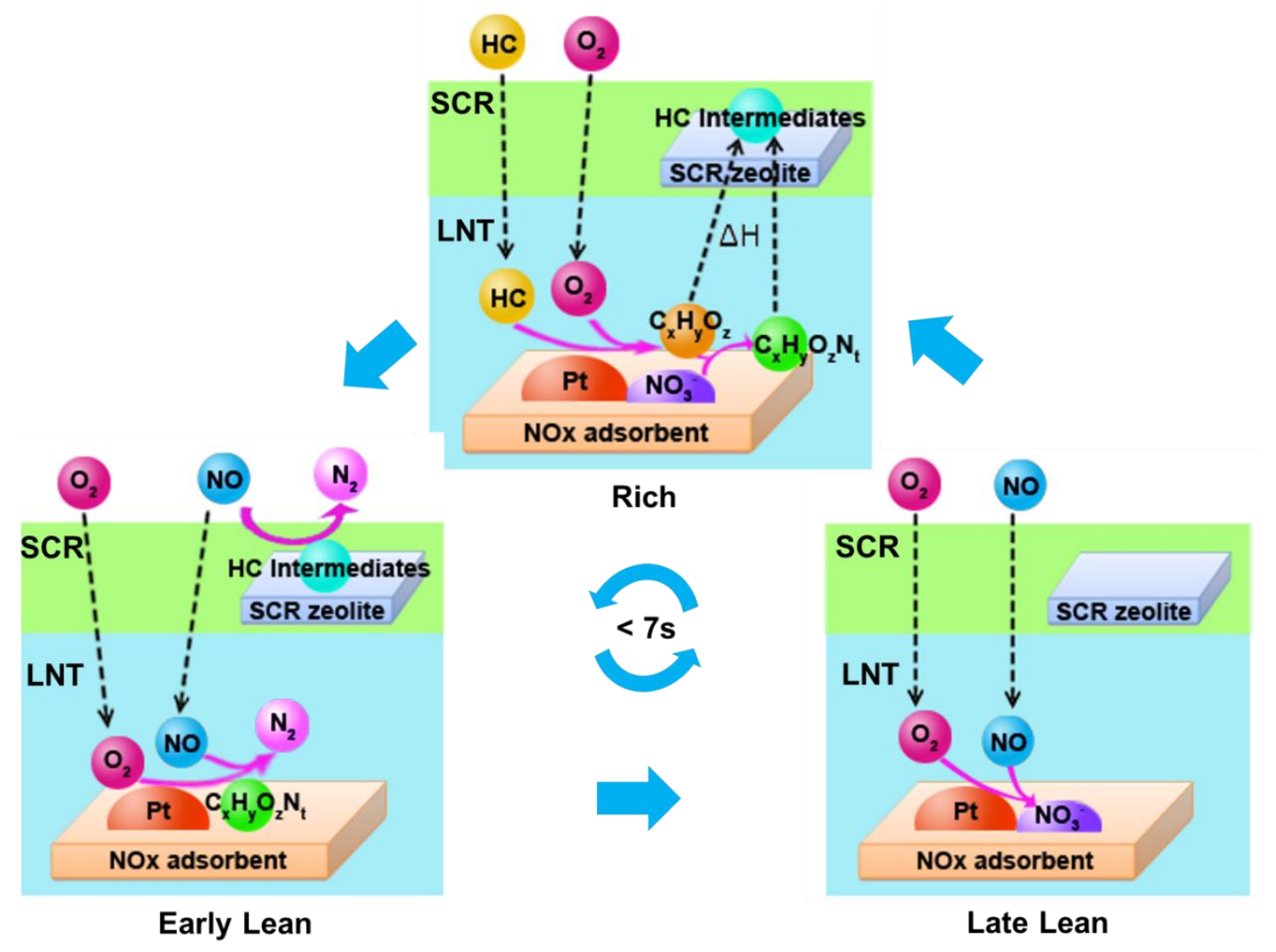


Fig. 8

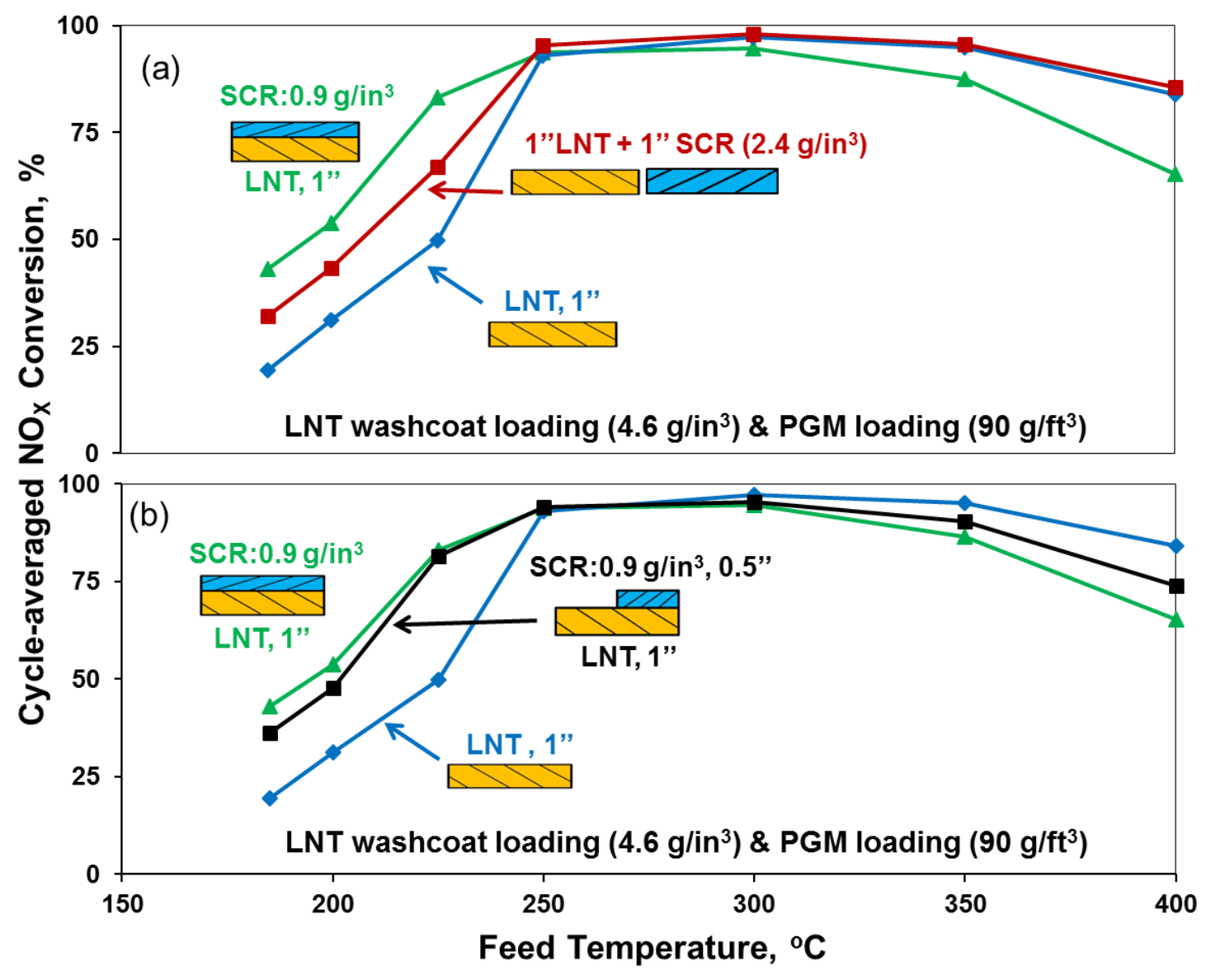


Fig. 9

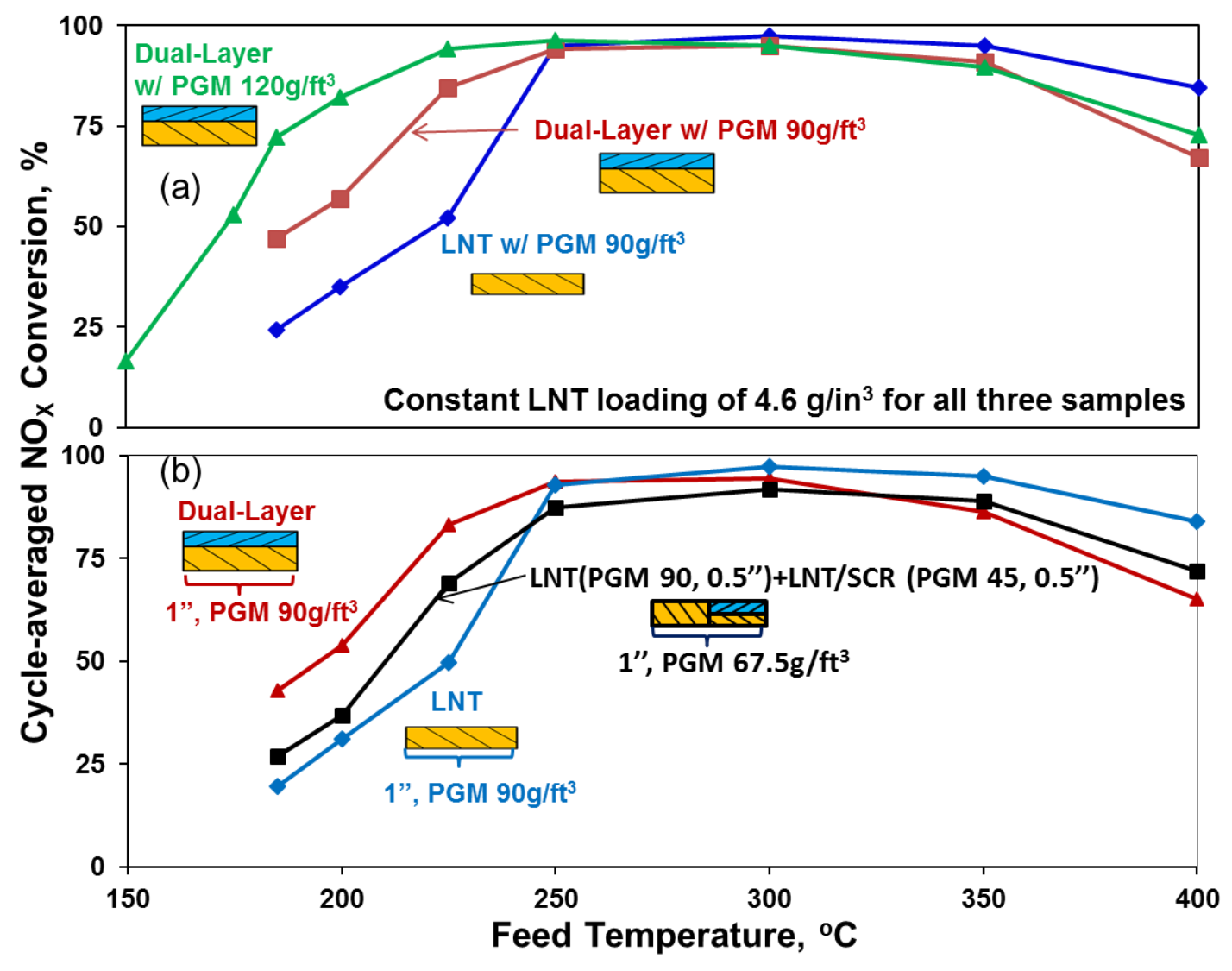

